\title{
Incidence of phantom limb phenomena after lower limb amputations in a Singapore tertiary hospital
}

\author{
Eliza I-Lin Sin ${ }^{1}$, Sze Ying Thong ${ }^{2}$, mBBS, MMed, Keah-How Poon ${ }^{3}$, MBBS, MMed
}

\begin{abstract}
INTRODUCTION Phantom limb sensations (PLS), phantom limb pain (PLP) and stump pain (SP) are well-recognised postamputation phenomena. However, there is a dearth of related epidemiological data in Asian populations. This study was conducted to fill the information gap.

METHODS Telephone interviews were conducted with patients who underwent lower limb amputations at a tertiary hospital in Singapore. Information was obtained on phantom limb characteristics, perioperative pain and functional assessment.

RESULTS A total of 159 patients underwent amputations over a 31-month period. At the time of the interview, 47 patients had died and 66 were contactable, of whom 49 patients were interviewed. Of these, 31 (63\%) patients experienced PLS. 22 patients had postoperative pain, with 9 having both PLP and SP, 3 having PLP alone and 10 having SP alone. Among the 12 patients with PLP, at least 6 (50\%) experienced constant or daily pain and 7 (58\%) scored their pain as moderate-to-severe. Among those with PLP and/or SP $(n=22), 5$ were distressed by the pain, 11 were on analgesics and 3 received medical follow-up. 7 (32\%) patients reported functional limitations secondary to PLP or SP. Altogether, 28 (57\%) patients were wheelchair or bed bound.

CONCLUSION The incidence of PLP was $25 \%$ in our cohort. Although this is lower than that reported in other studies, it remains significant, as some patients suffered moderate-to-severe pain. The difference in incidence may be due to differences in the ethnic composition and/or indications for amputation in our group. Follow-up and care could improve the outcomes in these patients.
\end{abstract}

Keywords: chronic pain after amputation, phantom limb pain, phantom sensations, stump pain

Singapore Med J 2013; 54(2): 75-81

\section{INTRODUCTION}

Phantom limb complex is a term used to describe phantom limb sensations (PLS), phantom limb pain (PLP) and/or stump pain (SP). PLS is defined as any sensation, other than pain, in the absent limb. PLP is any painful sensation referred to the absent limb, while SP is pain localised in the stump. These elements often coexist in patients and may be difficult to differentiate. ${ }^{(1,2)}$ Phantom limb complex, which is not an uncommon phenomenon, can be chronic and distressing to patients.

Based on the current literature, the reported incidences of PLP vary from $47 \%-79 \% .^{(3-12)}$ This wide variation in the reported incidences may be attributable to differences in the study populations, methodologies, definitions and cut-off values used for the diagnosis of PLP, the time points of assessment and other factors. A majority of the published literature on the epidemiology of PLP comes from Caucasian populations, with patients undergoing traumatic amputations being the commonest subgroup of patients being investigated. There is, however, a paucity of relevant literature on Asian populations. Anecdotally, local amputees seldom experience or complain of PLP. Thus, the primary aim of this study was to determine the incidence of phantom limb phenomena in the local population. The secondary aims were: (a) to identify the risk factors associated with PLP; (b) to characterise the overall pain experience of patients with PLP; and (c) to understand the functional impact of PLP/SP in patients with PLP.

\section{METHODS}

Following approval from the institutional review board, all adult patients (> 18 years) who underwent lower limb amputations $(\mathrm{n}=159)$ at the National University Hospital, Singapore, between September 2007 and March 2010 were selected from the electronic records at the operating theatre. Demographic data, indications for surgery and details of the surgeries performed were obtained for all the selected patients.

Telephone interviews were conducted by two authors using a standardised script and questionnaire. The preferred language of the interviews was English, followed by Mandarin or a Chinese dialect. Informed verbal consent was obtained from all the participants prior to the interview. The data collected included the characteristics of phantom limb phenomena, perioperative pain as well as functional assessment. If the patient was unable to complete the interview due to language barriers, a proxy interview was performed using a translator. Three attempts were made to contact each patient, with each attempt being made on a different day. Patients were classified as not contactable after three failed attempts.

\footnotetext{
${ }^{1}$ Yong Loo Lin School of Medicine, National University of Singapore, ${ }^{2}$ Department of Anaesthesia, Singapore General Hospital, ${ }^{3}$ Department of Anaesthesia, National University Health System, Singapore

Correspondence: Dr Sze Ying Thong, Associate Consultant, Department of Anaesthesia, Singapore General Hospital, Outram Road, Singapore 169608. thongszeying@gmail.com
} 


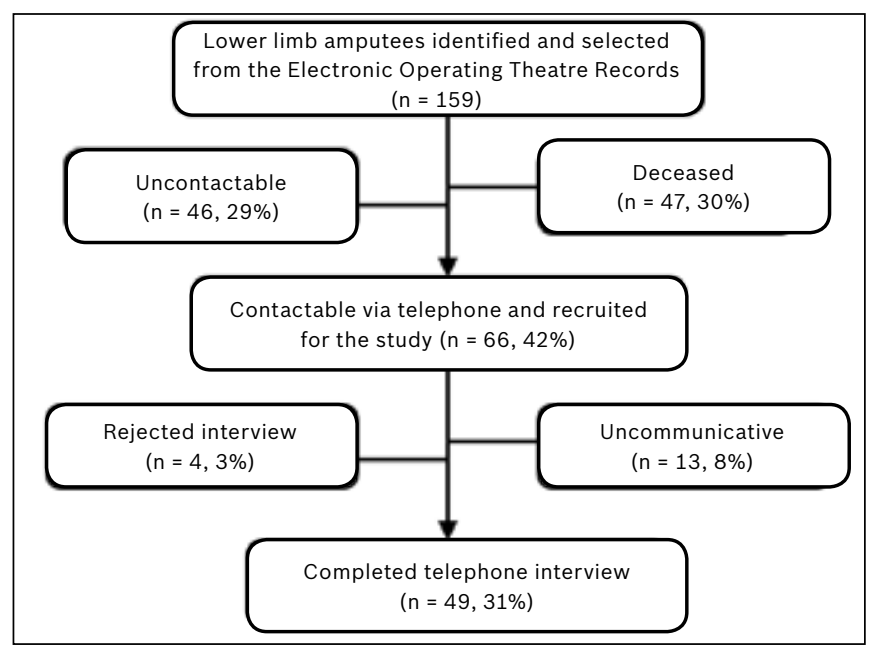

Fig. 1 Flowchart outlining the study shows the screening, recruitment and interview process.

The questionnaire comprised four sections: (a) PLS; (b) PLP; (c) SP; and (d) sequelae of pain or treatment. The presence of PLS was elicited by asking if the patient felt the presence of the amputated leg, and if affirmative, the time of its onset was determined. Kinaesthetic, kinetic and super-added sensations were addressed in the next four questions. The presence of PLP was determined by asking if the phantom limb was painful. Pain characteristics, including frequency, site and severity of pain, were also collected. Patients were also asked about pain over the operative site to determine the presence and severity of SP. The presence or absence of preamputation pain was also recorded. Information regarding any sequelae of pain and treatment received was obtained via questions regarding the impact of pain on mood, activity and function, as well as the types of treatment received for pain. Efforts were made to ensure that limitations in activity and function reported by patients were the result of pain and not due to the loss of limb following amputation.

The data were analysed using the Statistical Package for the Social Sciences for Windows version 16.0 (SPSS Inc, Chicago, IL, USA). Results were presented as mean \pm standard deviation, range or percentage values, as appropriate. Associations were analysed using Pearson's chi-square test. A p-value $<0.05$ was considered to be statistically significant.

\section{RESULTS}

Of the 159 patients who underwent lower limb amputations, 49 (31\%) patients completed the interviews, 47 (30\%) patients had died, 46 (29\%) were not contactable, 13 (8\%) were uncommunicative and 4 (3\%) declined to be interviewed (Fig. 1). The patients were, on average, contacted $17 \pm 8$ (range 4-29) months following amputation. The patients who were eventually interviewed were similar in characteristics to the group of patients selected initially. Out of the 49 patients interviewed, 46 (94\%) were of East Asian origin. Singapore, a migrant city-state with a predominantly Chinese population, was made up of approximately $77.0 \%$ Chinese, $14.8 \%$ Malays and $7.0 \%$ Indians, according to the 2010 population census. ${ }^{(13)}$ Although these three main ethnic groups were represented in our survey, Malay patients
Table I. Characteristics of selected $(n=159)$ and interviewed ( $n=49)$ patients who underwent lower limb amputations.

\begin{tabular}{|c|c|c|}
\hline \multirow[t]{2}{*}{ Characteristic } & \multicolumn{2}{|c|}{ No. (\%) } \\
\hline & $\begin{array}{l}\text { Selected } \\
\text { patients }\end{array}$ & $\begin{array}{c}\text { Interviewed } \\
\text { patients }\end{array}$ \\
\hline \multicolumn{3}{|l|}{ Ethnicity } \\
\hline Chinese & $81(51)$ & $23(47)$ \\
\hline Malay & $50(31)$ & 19 (39) \\
\hline Indian & $16(10)$ & $4(8)$ \\
\hline Caucasian & $3(2)$ & $1(2)$ \\
\hline Others & $9(6)$ & $2(4)$ \\
\hline \multicolumn{3}{|l|}{ Gender } \\
\hline Male & $104(65)$ & $37(76)$ \\
\hline Female & $55(35)$ & $12(25)$ \\
\hline \multicolumn{3}{|l|}{ Age range (yrs) } \\
\hline $20-29$ & $3(2)$ & 0 \\
\hline 30-39 & $6(4)$ & $2(4)$ \\
\hline $40-49$ & $10(6)$ & $3(6)$ \\
\hline $50-59$ & $34(21)$ & $14(29)$ \\
\hline $60-69$ & $49(31)$ & $17(35)$ \\
\hline $70-79$ & $37(23)$ & $11(22)$ \\
\hline 80-89 & $16(10)$ & $2(4)$ \\
\hline $90-99$ & $4(3)$ & 0 \\
\hline \multicolumn{3}{|l|}{ Type of surgery } \\
\hline Below knee & $99(62)$ & $35(71)$ \\
\hline Above knee & $54(34)$ & $10(20)$ \\
\hline Through knee & $4(3)$ & $2(4)$ \\
\hline Hip disarticulation & $1(1)$ & $1(2)$ \\
\hline Hemipelvectomy & $1(1)$ & $1(2)$ \\
\hline \multicolumn{3}{|l|}{ Side of surgery } \\
\hline Left & $80(50)$ & $27(55)$ \\
\hline Right & $70(44)$ & $21(43)$ \\
\hline Bilateral & $9(6)$ & $1(2)$ \\
\hline \multicolumn{3}{|l|}{ Indication for surgery } \\
\hline Infection related to diabetes mellitus & $86(54)$ & $23(47)$ \\
\hline Atherosclerosis & $53(34)$ & $16(33)$ \\
\hline Trauma & $12(8)$ & $4(8)$ \\
\hline Tumour & $2(1)$ & $1(2)$ \\
\hline Thromboembolism or acute ischaemia & $6(4)$ & $5(10)$ \\
\hline
\end{tabular}

disproportionately constituted $31 \%$ of our cohort. 37 (76\%) of the interviewed patients were men. The mean age at the time of amputation was $62 \pm 11$ (range 38-87) years. The indications for surgery, and the type and site of surgery among the patients who underwent lower limb amputations are presented in Table I.

PLS was reported by 31 (63\%) patients. The phenomenon was found to start soon after surgery, with the median time of onset being immediate. PLS included kinetic, kinaesthetic and superadded sensations. Kinetic sensations of movement in the phantom limb were experienced by 14 (45\%) patients. Two kinaesthetic phenomena were elicited from the patients interviewed: telescoping ( $\mathrm{n}=11,36 \%$ ) and phantom limb in an awkward position ( $n=4,13 \%$ ). Super-added sensations of objects such as socks or shoes on the phantom limb were reported by 8 (26\%) patients (Table II). Among the 49 patients who completed the interviews, 12 (25\%) patients reported PLP and 19 (39\%) had SP. $50 \%$ of the patients with PLP reported having pain daily, while nine patients had concurrent PLP and SP. Seven patients with PLP and seven patients with SP reported pain of moderate-to-severe intensity on a verbal descriptor scale. Nearly a quarter of the patients with PLP or SP reported being distressed by their pain (Fig. 2 \& Table III). 
Table II. Characteristics of patients with phantom limb sensation ( $n=31)$.

\begin{tabular}{lr}
\hline Phantom limb sensation & No. (\%) \\
\hline Kinetic & $14(45)$ \\
$\quad$ Movement in the phantom limb & \\
Kinaesthetic & $4(13)$ \\
$\quad$ Phantom limb in an abnormal position & $11(36)$ \\
$\quad$ Telescoping in the phantom limb & \\
Super-added & $8(26)$ \\
\hline
\end{tabular}

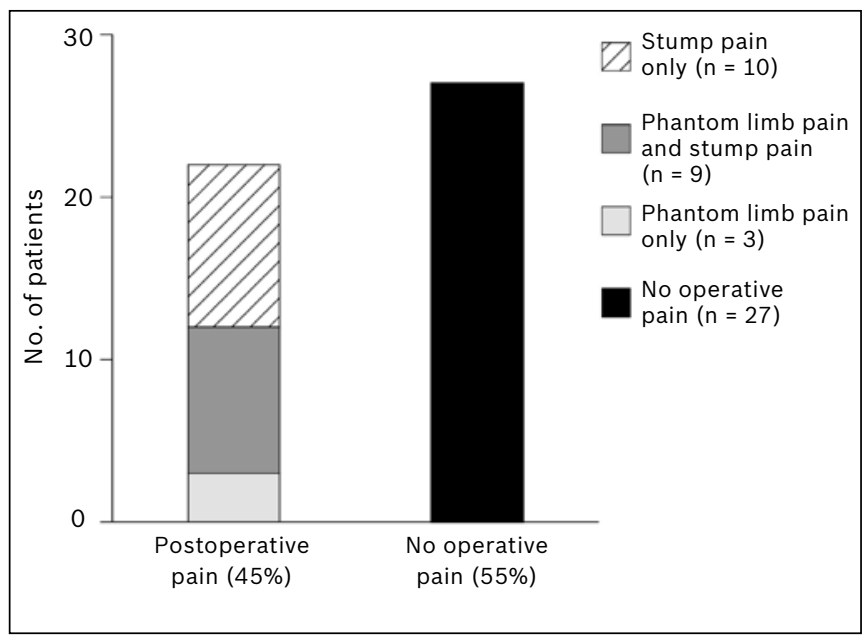

Fig. 2 Graph shows the incidence of postoperative pain in patients.

Among the 22 patients who reported PLP, SP or both, only 3 $(14 \%)$ were being followed up by a doctor. Half of these patients were not receiving any analgesics. Among the seven patients who reported PLP of moderate-to-severe intensity, 5 (71\%) were not followed up by a medical professional and 1 (14\%) was not on any form of analgesics. Three patients with PLP were distressed by their PLP. Among the seven patients who reported SP of moderate-to-severe intensity, 5 (71\%) were not followed up by any medical professional and 1 (7\%) was not on any form of analgesics. Four patients with SP were distressed by their pain. Among all the patients who were distressed by pain, one patient was not on medication and one was not on follow-up with a medical professional. Seven of all patients with PLP or SP had significant limitation related to either work or leisure, or needed a caregiver as a result of their pain. A majority of the lower limb amputees $(n=27,55 \%)$ in our cohort were wheelchair bound, while $1(2 \%)$ patient was bed bound, $16(33 \%)$ patients were ambulatory with the help of a prosthesis, and $5(10 \%)$ patients relied on crutches.

The association between PLP and risk factors such as ethnicity, gender, age, and type, side and indications for surgeries, as well as the presence of preoperative pain and SP are presented in Table IV. No statistically significant association was found between PLS and risk factors such as ethnicity, gender, age, and type and side of surgeries. There was a positive association between PLP and the indications for amputation $(p=0.01)$, with all five patients who had traumatic and oncological amputations reporting PLP. Among the 16 patients with PLS who underwent
Table III. Characteristics of postoperative pain in the interviewed patients.

\begin{tabular}{|c|c|}
\hline Characteristic & No. (\%) \\
\hline \multicolumn{2}{|l|}{ Type of sensation present $(n=48)$} \\
\hline PLP & $12(25)$ \\
\hline SP & 19 (39) \\
\hline \multicolumn{2}{|l|}{ Frequency of PLP $(n=12)$} \\
\hline Constant & $1(8)$ \\
\hline Daily & $5(42)$ \\
\hline Once a week & $3(25)$ \\
\hline Once a month & $2(17)$ \\
\hline Less than once a month & $1(8)$ \\
\hline \multicolumn{2}{|l|}{ Site of PLP $(n=12)$} \\
\hline Toes & $4(33)$ \\
\hline Foot & $2(17)$ \\
\hline Below knee & $1(8)$ \\
\hline Above knee & $1(8)$ \\
\hline Multiple sites & $4(33)$ \\
\hline \multicolumn{2}{|l|}{ Severity of PLP (n=12) } \\
\hline Mild & $5(42)$ \\
\hline Moderate & $6(50)$ \\
\hline Severe & $1(8)$ \\
\hline \multicolumn{2}{|l|}{ Severity of SP $(n=19)$} \\
\hline Mild & $12(63)$ \\
\hline Moderate & $4(21)$ \\
\hline Severe & $3(16)$ \\
\hline \multicolumn{2}{|l|}{ Management of PLP or SP $(n=22)$} \\
\hline No follow-up & $16(73)$ \\
\hline Consults general practitioner & $1(5)$ \\
\hline Consults pain specialist & $2(9)$ \\
\hline Physical therapy & $3(14)$ \\
\hline Taking analgesia for pain $(n=22)$ & $11(50)$ \\
\hline Distressed by PLP or SP $(n=22)$ & $5(23)$ \\
\hline \multicolumn{2}{|c|}{$\begin{array}{l}\text { Limitations on activity due to phantom limb complex } \\
(n=22)\end{array}$} \\
\hline No & $15(68)$ \\
\hline Limits leisure activities & $3(14)$ \\
\hline Limits work & $3(14)$ \\
\hline Need for caregiver & $1(5)$ \\
\hline
\end{tabular}

PLP: phantom limb pain; SP: stump pain

amputation due to infection secondary to diabetes mellitus, only 4 (25\%) patients reported PLP. Of the 12 patients with PLS who underwent amputation due to peripheral vascular disease, only $3(25 \%)$ reported PLP. PLP was also associated with SP $(p=0.003)$, with $9(75 \%)$ of the 12 patients with PLP also reporting SP. There was an association between PLP and the site of surgery ( $p=0.031$ ), with $75 \%$ of patients who had above-knee amputations with PLS and 25\% of those who had below-knee amputations with PLS reporting PLP. There was a positive association between SP and gender $(p=0.02)$, with 8 of $12(67 \%)$ women experiencing SP compared to 11 of $37(30 \%)$ men.

\section{DISCUSSION}

The primary aim of this study was to determine the incidence of phantom limb phenomena among patients who had undergone lower limb amputations in the local population. The secondary aims were: (a) identification of the risk factors of PLP in these patients; (b) characterisation of the overall pain experience of these patients; and (c) increasing our understanding of the functional impact of pain in these patients with PLP by examining phantom pain-related disability in a predominantly Asian cohort. 
Table IV. Association of phantom limb pain with analysed risk factors in patients with phantom limb sensation $(n=31)$.

\begin{tabular}{|c|c|c|c|}
\hline \multirow[t]{2}{*}{ Risk factor } & \multicolumn{2}{|c|}{ No. (\%) } & \multirow[t]{2}{*}{ p-value } \\
\hline & $\begin{array}{l}\text { PLP present } \\
(n=12)\end{array}$ & $\begin{array}{l}\text { PLP absent } \\
(n=19)\end{array}$ & \\
\hline Ethnicity & & & 0.49 \\
\hline Chinese & $7(58)$ & $9(47)$ & \\
\hline Malay & $3(25)$ & $7(37)$ & \\
\hline Indian & 0 & $2(17)$ & \\
\hline Caucasian & $1(8)$ & 0 & \\
\hline Others & $1(8)$ & $1(8)$ & \\
\hline Gender & & & 0.19 \\
\hline Male & $8(67)$ & $14(74)$ & \\
\hline Female & $4(33)$ & $5(26)$ & \\
\hline Age range (yrs) & & & 0.16 \\
\hline $30-39$ & $1(8)$ & $1(8)$ & \\
\hline $40-49$ & $3(25)$ & 0 & \\
\hline $50-59$ & $4(33)$ & $4(21)$ & \\
\hline $60-69$ & $2(17)$ & $9(47)$ & \\
\hline $70-79$ & $2(17)$ & $4(21)$ & \\
\hline $80-89$ & 0 & $1(8)$ & \\
\hline Type of surgery & & & 0.031 \\
\hline Below knee & $5(42)$ & $15(79)$ & \\
\hline Above knee & $6(50)$ & $2(11)$ & \\
\hline Through knee & 0 & $2(11)$ & \\
\hline Hemipelvectomy & $1(8)$ & 0 & \\
\hline Side of surgery & & & 0.74 \\
\hline Left & $6(50)$ & $11(58)$ & \\
\hline Right & $6(50)$ & $8(42)$ & \\
\hline Indications for surgery & & & 0.01 \\
\hline Infection related to DM & $4(33)$ & $10(53)$ & \\
\hline Atherosclerosis & $2(17)$ & $5(26)$ & \\
\hline Trauma & $4(33)$ & 0 & \\
\hline Tumour & $1(8)$ & 0 & \\
\hline $\begin{array}{l}\text { Thromboembolism or } \\
\text { acute ischaemia }\end{array}$ & $1(8)$ & $4(21)$ & \\
\hline Preoperative pain & $5(42)$ & $10(53)$ & 0.41 \\
\hline Stump pain & $9(75)$ & $4(21)$ & 0.003 \\
\hline
\end{tabular}

The exact aetiologies of PLS and PLP are unknown. It is widely believed that PLP is the result of nerve injury, followed by a series of changes in the peripheral and central nervous systems. Neuromas formed after limb amputation or dorsal root ganglia may display spontaneous and abnormal activities after amputation, which may be activated in part by the sympathetic

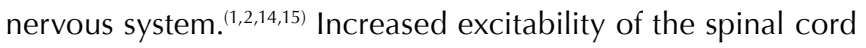
neurons and increased activity of $\mathrm{N}$-methyl $\mathrm{D}$-aspartate receptor (NMDA)-operated systems, coupled with cerebral reorganisation, are also said to be involved in generating phantom pains. These changes also play a role in the induction and maintenance of chronic PLP. ${ }^{(1,2,14,15)}$

PLS is believed to be universally present following amputation, and is thought to be less bothersome than PLP or SP. ${ }^{(2,8)}$ It can be difficult to differentiate between SP and PLP, especially in the early postamputation phase. The incidence of PLP was found to range from $47 \%$ to $79 \%$ in most studies performed mainly on Caucasian populations and patients whose amputations were a result of traumatic injuries. ${ }^{(3-8,10,11)}$ On the other hand, SP is common in the early postoperative period, but subsides in most patients with healing. ${ }^{(1)}$ Common pathologies such as infection and bone spurs, as well as adherent and wrinkled scars, are common causes of SP. Persistent abnormal excitability of the sensory nerve endings in a neuroma formed after amputation is considered to be one of the mechanisms leading to chronic SP following amputation. The reported incidence of SP varies between $32 \%$ and $93 \% .^{(3-6,8-12)}$

According to the current understanding of neuropathic pain, peripherally originating impulses induce SP, whereas centrally arising nerve impulses induce phantom pain. In a clinical setting, SP can be modulated by peripheral interventions such as local anaesthesia of the neuroma or peripheral nerve, while phantom pain is not affected by such peripheral interventions. ${ }^{(14)}$ SP and PLP are interrelated phenomena, and associations between the two have been found in several studies. ${ }^{(16,17)}$ The two conditions often coexist and are difficult to differentiate. Several factors can affect the occurrence and extent of phantom pain. Reports suggest that pre- and postoperative pains can influence subsequent PLP. $(1,2,11,16,18,19)$ Some authors have put forward that certain indications for amputation predispose a patient to the development of PLP and SP. For instance, Weiss and Lindell found that amputees with a history of ischaemia, gangrene and amputation had higher pain levels. ${ }^{(20)}$ Ephraim et al reported that younger patients with depressed moods and two or more comorbidities also tend to report greater intensity of PLP and SP. ${ }^{(8)}$

The incidences of PLS, PLP and SP in our cohort were 63\%, $25 \%$ and $39 \%$, respectively, which were generally lower than those reported in earlier studies of western populations..$^{(5,8,10)}$ This finding is in agreement with our clinical experience as well. In addition, a positive association was seen between PLP and patients undergoing amputations for traumatic and oncological indications, as well as more proximal amputations (above knee). Patients undergoing amputations for traumatic and oncological indications, as well as women, were also found to have a positive association with SP. However, no association was seen between PLP or SP and age, ethnicity and preamputation pain.

The findings for our local cohort differed in some important aspects when compared to those of most published studies. First, our population was predominantly Asian, comprising mostly Chinese and Malay patients, while most previous studies had largely Caucasian populations. ${ }^{(13)}$ Caucasians have been shown to have higher levels of PLP when compared to non-Caucasians, ${ }^{(20)} \mathrm{a}$ phenomenon that may be associated with a variety of biological, social and psychological mechanisms. ${ }^{(21-23)}$ It is possible that ethnic factors influence the activity of higher nerve centres that modulate pain through the activation of descending neural inhibitory controls. Ethnic factors may also have a major influence on the patient's emotional and behavioural responses to pain. ${ }^{(24,25)}$ The authors only know of one previous study on PLP in an Asian population. Husum et al studied 57 severely injured adult survivors of landmine accidents in Cambodia and Kurdistan more than one year after the accident and found the incidence of PLP in these patients to be $68 \% .^{(7)}$ The aetiology of amputations in 
the study was purely traumatic, and this might be the reason for the higher incidence of PLP found by these authors as compared to our incidence of $25 \%$. Although all four patients who underwent lower limb amputations due to trauma in our study also developed PLP, the number of patients in our cohort was too small for us to draw any meaningful conclusions.

Second, a majority of amputations in our study (85\%) were associated with lower limb infections in patients with diabetes mellitus and/or peripheral vascular disease. A marked difference in the observed spectrum of indications for amputation between our study and most other Caucasian studies might account for the difference in the reported incidences of PLP and SP. In contrast to our study population, Caucasian populations have fewer indications for amputation, and the usual indications are mainly neoplasm and trauma. ${ }^{(3-8,10-12)}$ Third, our population was generally older, with a mean age of 62 years, which is in contrast to other studies that featured younger and middle-aged patients. ${ }^{(4-6,8)}$ Age has been reported to correlate with PLP, with a study by Gallagher et al reporting that old age was positively related to the prevalence and severity of PLP. ${ }^{(6)}$ Quite to the contrary, we did not find any association between age and PLP in our adult local population. Age also has a confounding effect on the relationship between aetiology and the incidence of PLP. Age-related diseases such as diabetes mellitus and peripheral vascular diseases are more prevalent in older populations, while younger patients tend to be more associated with traumatic amputations. This association is further complicated by the fact that economically inactive elderly patients may have different health-seeking behaviours, as social factors such as the lack of health insurance coverage and lower socioeconomic status may also influence the utilisation of medical resources by this group of patients who have poorer outcomes. ${ }^{(26,27)}$ Thus, taking age alone as a risk factor, without accounting for other related factors associated with this variable, would likely introduce bias in the results of a study.

Two studies have reported incidences of PLP that are similar to ours. Bosmans et al reported an incidence of $32 \%$ in their study, ${ }^{(28)}$ while Alamo Tomillero et al found the incidence of PLP to be $26 \%$ among patients undergoing amputation for chronic arterial ischaemia. ${ }^{(29)}$ Interestingly, even though these two studies were performed on Caucasian patients, a predominantly higher proportion of patients had peripheral vascular disease in Bosmans et al's study, while a majority of the patients in Alamo Tomillero et al's study had diabetes mellitus. These findings are similar to the indications for surgery observed in our population.

We found that more proximal (above knee) amputations had a positive association with PLP, which was in agreement with the study by Gallagher et al. ${ }^{(6)}$ However, most other studies have reported the occurrence of PLP to be independent of the level of amputation. ${ }^{(16,17,30)}$ In general, more extensive amputation in a patient as a result of diabetes mellitus or vascular insufficiency usually indicates more extensive disease. It is also likely that such patients would go through progressively proximal levels of amputations to treat their gangrenous limbs. Repeated surgical procedures have been suggested to affect the development of PLP and SP. For instance, in a large multicentre study, Crombie et al found that surgery contributed to chronic pain in $22.5 \%$ of patients. ${ }^{(31)}$

Preamputation pain was found to predict the development of PLP in several studies..$^{(1,2,11,16,18,19)}$ This seems biologically plausible as mechanisms such as sensitisation and wind-up phenomena, as well as the concept of altered neuromatrix signature, might explain such an association. In fact, some authors have taken this a step further to examine the effects of aggressive preamputation pain control on the incidence of PLP after surgery. A prospective study by Jahangiri et al of 24 patients undergoing lower limb amputation found that perioperative epidural infusion of morphine and bupivacaine, alone or in combination, was effective in preventing PLP in patients with preexisting limb pain. ${ }^{(32)}$ However, a systematic review by Halbert et al of three preemptive epidural trials found inconsistent evidence to support its use in preventing postoperative PLP. ${ }^{(33)}$ In our study, we did not find any association between preamputation pain and PLP.

While some studies have reported that PLP was more common in women, ${ }^{(6,28)}$ other studies, including ours, found no such gender-based differences in the occurrence of PLP. ${ }^{(5,11)}$ In most studies, small sample sizes precluded a meaningful conclusion regarding the occurrence of PLP based on gender. In our study, women had a positive association with SP. Differences in the way that women and men perceive and experience pain are well known. Women generally are more burdened by pain and are more willing to seek healthcare. Derbyshire suggests that biological as well as psychosocial differences such as differences in body size, organisation of the nervous system, skin thickness, hormonal responses, and differences in social expectations and psychological traits may explain gender differences in pain experience. $^{(34)}$ Furthermore, according to some studies, men and women tend to use different coping styles when in pain. ${ }^{(34-36)}$

The lack of a standardised definition for PLP and heterogeneity among the patient groups recruited by the various reports hinder efforts to make comparisons across studies. For instance, in the study by Bosmans et al, PLP was defined as daily pain, and consequently, patients with less frequent occurrence of symptoms were excluded. ${ }^{(28)}$ Meanwhile, the incidence of $26 \%$ reported in the study by Alamo Tomillero et al was for patients who had acute PLP in the first week following amputation. ${ }^{(29)}$ As is generally known, PLP is frequently episodic, and in a minority of patients, the onset of pain may be delayed. ${ }^{(5,11)}$ The nonuniform definitions of PLP adopted by the authors in these two studies predispose them to an underdiagnosis of PLP, which most likely accounts for the low incidences reported. In our study, patients who had experienced PLP once a month or less frequently were included. Although the clinical significance of such infrequent episodes of PLP is debatable, in our study, patients who experienced PLP once a week or less frequently represented $50 \%$ of all patients with PLP. It is therefore possible that our results may in fact have overreported the incidence of PLP in our population. In addition 
to the varying definitions of PLP and SP, selection and responder biases were found in many studies that recruited patients from rehabilitation clinics or via postal surveys..$^{(3-6,8,10,20)}$ Most studies generally evaluated limited aspects of PLP and measured it at only one point in time. Prospective longitudinal surveys were plagued by high dropout rates, in part due to significant mortality after amputation. ${ }^{(28)}$

There is more agreement with respect to the nature of PLP and SP in the literature. Typically, PLP and SP are episodic, and there are variations in their reported intensities. A significant proportion of patients with PLP and SP are bothered by pain..$^{(5,8,10,37)}$ In our study, close to three-quarters of the patients who had moderateto-severe PLP and SP were not being followed up by medical practitioners. Most patients with moderate-to-severe PLP and SP were on analgesics. Interestingly, only five patients reported being distressed by their PLP or SP. This finding has important implications for individuals and medical professionals involved in the care of amputees, as it indicates that a more proactive approach may be needed to better manage the amputee's overall pain experience.

There were several limitations to this study. Firstly, the number of patients surveyed in our study was small ( $n=49)$, although it was comparable to many published studies in the literature. ${ }^{(9,11,12,17,20,29,37)}$ Significantly, of the 159 patients originally selected for contact, about one-third of patients had died while another one-third were not contactable. It is therefore possible that the actual incidence of PLP among patients who underwent lower limb amputations at our hospital was much higher given the large number of patients for whom the presence of PLP or SP could not be determined.

Secondly, as our study was retrospective in nature, there was a potential for recall bias on the part of patients. To minimise this, most questions about pain quality and intensity were asked to determine the patients' pain status at the time of interview. The authors acknowledge that such an approach would introduce an element of underestimation in the overall incidence of postamputation pain among these patients due to differences in the time after surgery at which these patients were interviewed. Patients were contacted at an average of 17 (range 4-29) months after amputation. It is possible that the incidence of PLP may have been underreported for patients who were contacted several months after amputation. However, as several reports have indicated that PLP and SP have early onsets, typically within days of amputation, the number of patients for whom PLP was underreported is likely to have been small in our study. ${ }^{(11)}$

Thirdly, we did not analyse other possible risk factors for the development of PLP or SP. These include the possible influence of regional anaesthesia or the timing and role of preemptive analgesia in preventing PLP and SP. Current evidence is not in strong support of any one anaesthetic technique, ${ }^{(10,32,33,38-44)}$ and multimodal analgesia supplying good postoperative pain control is likely to provide a greater impact. ${ }^{(45-47)}$ Psychological factors such as anxiety or depression may affect the onset, course and severity of pain in these patients. According to some authors, cognitive-emotional sensitisation also contributes to the altered nociceptive processing seen in PLP patients. ${ }^{(48,49)}$

In conclusion, our study reported the incidence of phantom limb phenomena in a predominantly Asian and multiracial population in Singapore. To the authors' knowledge, this is the first study that has published local epidemiological data on PLP in patients who underwent lower limb amputations. The incidence of PLP locally appears to be lower than that reported internationally, and this finding concurs with the authors' general clinical experience. We hypothesise that the difference in reported incidences among various studies might be related to the differences in the ethnic composition and indications for amputations in these cohorts.

Our search for risk factors of PLP among local patients has, however, yielded more questions than answers. Our incidence of PLP at 25\%, while low, remained significant. Nearly three-quarters of patients with PLP did not consult a doctor despite over half of these patients reporting moderate-to-severe pain. Less than a quarter of patients with PLP or SP reported being distressed by their pain, suggesting that follow-up by physicians may not be required for all patients with PLP or SP and that the use of analgesics on a needs-only basis may be sufficient for patients with mild pain and those who are not distressed by their pain. Improved understanding about the incidence of PLP and the characteristics of the pain experience among patients with PLP may help to improve the care of amputees. This study forms a basis for future research on predictors of the development of PLP, measures to prevent and treat PLP, and the prospective longterm follow-up of amputees.

\section{REFERENCES}

1. Nikolajsen L, Jensen TS. Phantom limb pain. Br J Anaesth 2001; 87:107-16.

2. Flor H, Nikolajsen L, Staehelin Jensen T. Phantom limb pain: a case of maladaptive CNS plasticity? Nat Rev Neurosci 2006; 7:873-81.

3. Wartan SW, Hamann W, Wedley JR, McColl I. Phantom pain and sensation among British veteran amputees. Br J Anaesth 1997; 78:652-9.

4. Smith DG, Ehde DM, Legro MW, et al. Phantom limb, residual limb, and back pain after lower extremity amputations. Clin Orthop Relat Res 1999; 361:29-38.

5. Ehde DM, Czerniecki JM, Smith DG, et al. Chronic phantom sensations, phantom pain, residual limb pain, and other regional pain after lower limb amputation. Arch Phys Med Rehabil 2000; 81:1039-44.

6. Gallagher P, Allen D, Maclachlan M. Phantom limb pain and residual limb pain following lower limb amputation: a descriptive analysis. Disabil Rehabil 2001; 23:522-30.

7. Husum H, Resell K, Vorren G, et al. Chronic pain in land mine accident survivors in Cambodia and Kurdistan. Soc Sci Med 2002; 55:1813-6.

8. Ephraim PL, Wegener ST, MacKenzie EJ, Dillingham TR, Pezzin LE. Phantom pain, residual limb pain, and back pain in amputees: results of a national survey. Arch Phys Med Rehabil 2005; 86:1910-9.

9. Richardson C, Glenn S, Nurmikko T, Horgan M. Incidence of phantom phenomena including phantom limb pain 6 months after major lower limb amputation in patients with peripheral vascular disease. Clin J Pain 2006; 22:353-8.

10. Ong BY, Arneja A, Ong EW. Effects of anesthesia on pain after lower-limb amputation. J Clin Anesth 2006; 18:600-4.

11. Hanley MA, Jensen MP, Smith DG, et al. Preamputation pain and acute pain predict chronic pain after lower extremity amputation. J Pain 2007; 8:102-9. 
12. Probstner D, Thuler LC, Ishikawa NM, Alvarenga RM. Phantom limb phenomena in cancer amputees. Pain Pract 2010; 10:249-56.

13. Department of Statistics. Census of Population 2010. Singapore: Ministry of Trade and Industry, 2010.

14. Zimmermann M. Pathobiology of neuropathic pain. Eur J Pharmacol 2001; 429:23-37.

15. Flor H. Phantom-limb pain: characteristics, causes and treatment. Lancet Neurol 2002; 1:182-9.

16. Nikolajsen L, Ilkjaer S, Kroner K, Christensen JH, Jensen TS. The influence of preamputation pain on postamputation stump and phantom pain. Pain 1997; 72:393-405.

17. Montoya P, Larbig W, Grulke N, et al. The relationship of phantom limb pain to other phantom limb phenomena in upper extremity amputees. Pain 1997; 72:87-93.

18. Perkins FM, Kehlet H. Chronic pain as an outcome of surgery. A review of predictive factors. Anesthesiology 2000; 93:1123-33.

19. Bloomquist T. Amputation and phantom limb pain: a pain-prevention model. AANA J 2001; 69:211-7.

20. Weiss SA, Lindell B. Phantom limb pain and etiology of amputation in unilateral lower extremity amputees. J Pain Symptom Manage 1996; 11:3-17.

21. Campbell CM, Edwards RR, Fillingim RB. Ethnic differences in responses to multiple experimental pain stimuli. Pain 2005; 113:20-6

22. Rahim-Williams FB, Riley JL 3rd, Herrera D, et al. Ethnic identity predicts experimental pain sensitivity in African Americans and Hispanics. Pain 2007; 129:177-84

23. Edwards RR, Doleys DM, Fillingim RB, Lowery D. Ethnic differences in pain tolerance: clinical implications in a chronic pain population. Psychosom Med 2001; 63:316-23.

24. Edwards CL, Fillingim RB, Keefe F. Race, ethnicity and pain. Pain 2001; 94:133-7.

25. Portenoy RK, Ugarte C, Fuller I, Haas G. Population-based survey of pain in the United States: differences among white, African American, and Hispanic subjects. J Pain 2004; 5:317-28.

26. Hadley J, Steinberg EP, Feder J. Comparison of uninsured and privately insured hospital patients. Condition on admission, resource use, and outcome. JAMA 1991; 265:374-9.

27. Bradbury RC, Golec JH, Steen PM. Comparing uninsured and privately insured hospital patients: admission severity, health outcomes and resource use. Health Serv Manage Res 2001; 14:203-10.

28. Bosmans JC, Geertzen JH, Post WJ, van der Schans CP, Dijkstra PU. Factors associated with phantom limb pain: a 31/2-year prospective study. Clin Rehabil 2010; 24:444-53.

29. Alamo Tomillero F, Rodríguez de la Torre R, Caba Barrientos F, et al. Prospective study of prevalence and risk factors for painful phantom limb in the immediate postoperative period of patients undergoing amputation for chronic arterial ischemia. Rev Esp Anestesiol Reanim 2002; 49:295-301.

30. Kooijman CM, Dijkstra PU, Geertzen JH, Elzinga A, van der Schans CP. Phantom pain and phantom sensations in upper limb amputees: an epidemiological study. Pain 2000; 87:33-41.

31. Crombie IK, Davies HT, Macrae WA. Cut and thrust: antecedent surgery and trauma among patients attending a chronic pain clinic. Pain 1998; 76:167-71.

32. Jahangiri $M$, Jayatunga AP, Bradley JW, Dark $\mathrm{CH}$. Prevention of phantom pain after major lower limb amputation by epidural infusion of diamorphine, clonidine and bupivacaine. Ann R Coll Surg Engl 1994; 76:324-6.

33. Halbert J, Crotty M, Cameron ID. Evidence for the optimal management of acute and chronic phantom pain: a systematic review. Clin J Pain 2002; 18:84-92.

34. Derbyshire SWG. Gender, pain and the brain. Pain Clin Updat 2008; 16:1-4

35. Keogh E, Denford S. Sex differences in perceptions of pain coping strategy usage. Eur J Pain 2009; 13:629-34.

36. Cook AJ, Chastain DC. The classification of patients with chronic pain: age and sex differences. Pain Res Manag 2001; 6:142-51.

37. Whyte AS, Niven CA. Variation in phantom limb pain: results of a diary study. J Pain Symptom Manage 2001; 22:947-53.

38. Kissin I. Preemptive analgesia. Anesthesiology 2000; 93:1138-43.

39. Møiniche S, Kehlet H, Dahl JB. A qualitative and quantitative systematic review of preemptive analgesia for postoperative pain relief: the role of timing of analgesia. Anesthesiology 2002; 96:725-41.

40. Lambert AW, Dashfield AK, Cosgrove C, et al. Randomized prospective study comparing preoperative epidural and intraoperative perineural analgesia for the prevention of postoperative stump and phantom limb pain following major amputation. Reg Anesth Pain Med 2001; 26:316-21.

41. Nikolajsen L, Ilkjaer S, Christensen JH, Krøner K, Jensen TS. Randomised trial of epidural bupivacaine and morphine in prevention of stump and phantom pain in lower-limb amputation. Lancet 1997; 350:1353-7.

42. Ypsilantis E, Tang TY. Pre-emptive analgesia for chronic limb pain after amputation for peripheral vascular disease: a systematic review. Ann Vasc Surg 2010; 24:1139-46.

43. Borghi B, D'Addabbo M, White PF, et al The use of prolonged peripheral neural blockade after lower extremity amputation: the effect on symptoms associated with phantom limb syndrome. Anesth Analg 2010; 111:1308-15.

44. Halbert J, Crotty M, Cameron ID. Evidence for the optimal management of acute and chronic phantom pain: a systematic review. Clin J Pain 2002, 18:84-92.

45. Karanikolas M, Aretha D, Tsolakis I, et al. Optimized perioperative analgesia reduces chronic phantom limb pain intensity, prevalence, and frequency: a prospective, randomized, clinical trial. Anesthesiology 2011; 114:1144-54.

46. Grosu I, de Kock M. New concepts in acute pain management: strategies to prevent chronic postsurgical pain, opioid-induced hyperalgesia, and outcome measures. Anesthesiol Clin 2011; 29:311-27.

47. Fassoulaki A, Triga A, Melemeni A, Sarantopoulos C. Multimodal analgesia with gabapentin and local anesthetics prevents acute and chronic pain after breast surgery for cancer. Anesth Analg 2005; 101:1427-32.

48. Hill A. Phantom limb pain: a review of the literature on attributes and potential mechanisms. J Pain Symptom Manage 1999; 17:125-42.

49. Vase L, Nikolajsen L, Christensen B, et al. Cognitive-emotional sensitization contributes to wind-up-like pain in phantom limb pain patients. Pain 2011 152:157-62 